Cite this: New J. Chem., 2014, 38,1846

Received (in Montpellier, France) 10th December 2013,

Accepted 21st February 2014

DOI: 10.1039/c3nj01556d

www.rsc.org/njc

\section{Water and methanol adsorption on MOFs for cycling heat transformation processes $\dagger$}

\begin{abstract}
Felix Jeremias, ${ }^{\text {ab }}$ Dominik Fröhlich, ${ }^{\text {ab }}$ Christoph Janiak* ${ }^{\text {b }}$ and Stefan K. Henninger*a
Microporous materials with high water uptake capacity are gaining attention for low temperature heat transformation applications such as thermally driven adsorption chillers (TDCs) or adsorption heat pumps (AHPs). TDCs or AHPs are alternatives to traditional air conditioners or heat pumps operating on electricity or fossil fuels. By using solar or waste heat as the driving energy, TDCs or AHPs can minimize primary energy consumption. TDCs and AHPs are based on the evaporation and consecutive adsorption of coolant liquids, preferably water, under specific conditions. Their ranges of application, as well as their efficiencies, power densities and total costs, are substantially influenced by the microporosity and hydrophilicity of the employed sorption materials. Here, we briefly summarize current investigations, developments and possibilities of metal-organic frameworks (MOFs) compared to classical materials. With their high water uptake, MOFs surpass those materials, while, at the same time, the variability of the building blocks allows for tuning of the microporosity and hydrophobic/hydrophilic design, depending on the specific application.
\end{abstract}

\title{
Introduction
}

With almost 9 billion tonnes of oil equivalent in $2011,{ }^{1}$ the worldwide final energy consumption is still growing, thus

${ }^{a}$ Dept. Thermally Active Materials and Solar Cooling, Fraunhofer Institute for Solar Energy Systems ISE, Heidenhofstr. 2, 79110 Freiburg, Germany.

E-mail: stefan.henninger@ise.fraunhofer.de; Fax:+49 7614588 9000;

Tel: +4976145885104

${ }^{b}$ Institut für Anorganische Chemie und Strukturchemie, Universität Düsseldorf, 40204 Düsseldorf, Germany. E-mail: janiak@uni-duesseldorf.de;

Fax: +492118112287

$\dagger$ Electronic supplementary information (ESI) available. See DOI: 10.1039/c3nj01556d

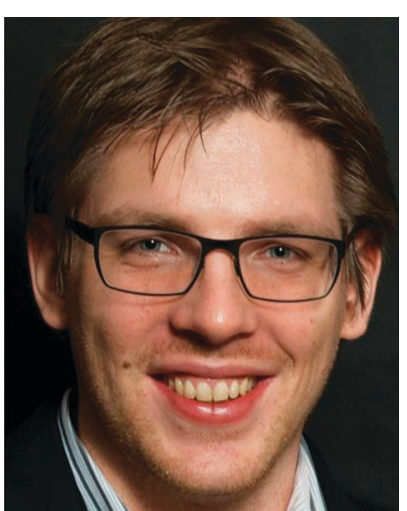

Felix Jeremias
Felix Jeremias studied chemistry at the University of Konstanz and graduated in 2010 working on reactions of mesoporous organosilica. Currently, he is finishing his PhD studies with Prof. Janiak (University of Düsseldorf) in close collaboration with the sorption materials team at Fraunhofer ISE. The subject of his thesis is the investigation of the thermodynamics and adsorptive properties of metal organic frameworks for heat transformation applications, and the development of specialized bulk and coating syntheses. raising concerns about future energy supplies, resources, and environmental impacts. Buildings account for $20 \%$ to $50 \%$ of the final energy consumption. ${ }^{2}$ Thus, the efficient use of energy for heating and cooling of buildings is a key issue towards a sustainable and secure energy supply in the future. Electrical power shortage due to grid overload is a well-known phenomenon already, and will probably increase with increasing demand for air conditioning in the emerging economies.

By the end of 2011, a total capacity of $234.6 \mathrm{GW}_{\text {th }}$ of solar thermal collectors was in operation. During summer time, collectors often produce more heat than needed for domestic hot water, thus, stagnation occurs at the same time when

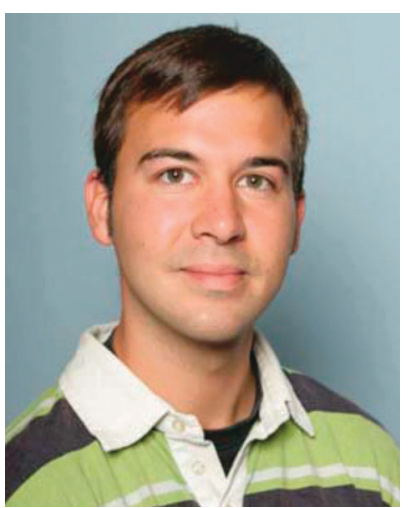

Dominik Fröhlich
Dominik Fröhlich received his MSc from the University of Konstanz in 2011 with work on enzymatic polymerization. $\mathrm{He}$ is now working on his $P h D$ in the Janiak group together with the Fraunhofer ISE. His research is focused on the optimization of MOFs for sorption-based chilling and heat pumping. In this context, D. Fröhlich is also investigating the degradation and structural changes of MOFs during adsorption processes. 
cooling demand increases. Low temperature heat $\left(<150{ }^{\circ} \mathrm{C}\right)$ is also available as a by-product of various industrial processes, but often simply rejected to the environment. As the cooling demand usually increases during the same period of the year, the use of thermally driven chillers is a promising alternative. This holds true even more for applications where heat rejection and cooling demand are independent of the season. Prime examples are data centres, where waste heat from power generation can be used for cooling of the computing systems.

Out of the different possibilities for thermally driven systems, solid sorption systems are seen as a very promising method. They are customizable, promise low-maintenance and use comparatively benign refrigerants like water or methanol.

\section{Principle process and possible working pairs}

Adsorption heat pumps and chillers feature a two-step process, which is depicted in Fig. 1.

The first figure of merit is the working fluid exchange within the thermodynamic cycle (Fig. S1 and S2 in ESI $\dagger$ ) and the

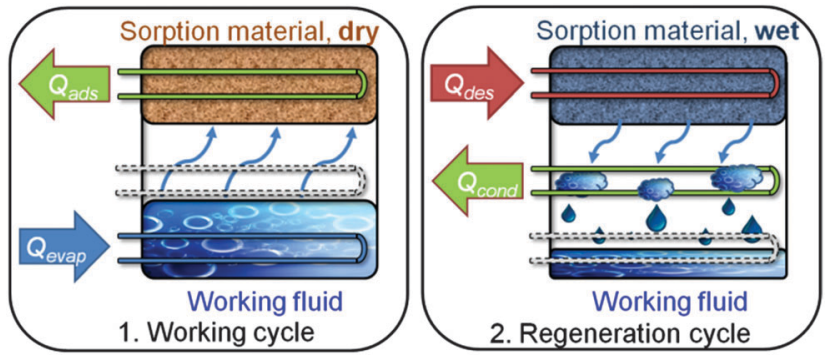

Fig. 1 Working scheme. During the working cycle, the working fluid evaporates, with evaporation enthalpy $Q_{\text {evap, }}$ and is consequently adsorbed, releasing adsorption enthalpy $Q_{\mathrm{ads}}$ at a higher temperature. During the regeneration cycle, desorption is realized by applying heat $Q_{\text {des }}$ to the porous material: the working fluid is released, condenses giving off $Q_{\text {cond }}$ and is available again. The appliance can serve as a chiller $\left(Q_{\text {evap }}=\right.$ useful cold, $Q_{\text {ads }}+Q_{\text {cond }}=$ rejected $)$, or as a heat pump $\left(Q_{\text {ads }}+Q_{\text {cond }}=\right.$ useful heat, $Q_{\text {evap }}$ from environment), depending on the adsorption properties (see ESI† for details). Copyright The Royal Society of Chemistry. ${ }^{3}$

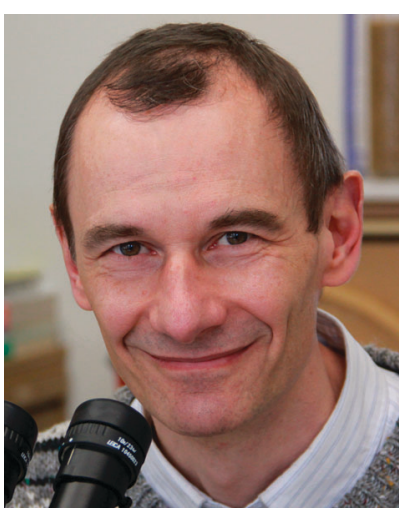

Christoph Janiak
Christoph Janiak studied chemistry at TU Berlin and the Univ. of Oklahoma, followed by a postdoc at Cornell Univ. and at BASF $A G$ and an Associate professorship at the Univ. of Freiburg. Since 2010 he has been full professor of Bioinorganic Chemistry and catalysis at the University of Düsseldorf with research interests in metal- and covalent-organic frameworks (MOFs, COFs), metal nanoparticles and catalysis.

second is the adsorption and evaporation enthalpy of the used gas-solid working pair (adsorptive-adsorbent). Thus, water as a working fluid is a natural choice because it is non-toxic, easily available and, above all, has a high evaporation enthalpy of $2500 \mathrm{~kJ} \mathrm{~kg}^{-1}$. Open systems, e.g., desiccant cooling systems, can also be realized based on water sorption. A minor drawback of closed systems with water as a refrigerant is the low vapor pressure of 1.0 to $6.0 \mathrm{kPa}$ under typical cooling conditions. Hence, besides the fact that the systems need to be vacuumtight, the mass transport may be limited due to the underlying diffusion regime. Consequently, short-chain alcohols like methanol and ethanol or ammonia are also of interest due to their higher evaporation pressures at low temperatures. They were already investigated in combination with, e.g., activated carbons. ${ }^{4}$ Moreover, these refrigerants are of principle interest for heat pump applications, as low temperature sources below $0{ }^{\circ} \mathrm{C}$, e.g., ambient air, can be used for evaporation. While ammonia is not appropriate for indoor use due to the high toxicity and compatibility problems, methanol is a good alternative to water, although it may be unstable at temperatures above $120{ }^{\circ} \mathrm{C} .{ }^{5}$

\section{Materials}

Choosing the appropriate adsorbent is governed by several figures of merit: as the thermal mass of the adsorbent has to be costly chilled down and reheated during every working cycle, the porosity should be as high as possible for better efficiency. Depending on the boundary conditions given by the application (desired evaporation and condensation temperatures, and available regeneration temperature), adsorption-desorption must take place at appropriate relative pressures $p / p_{0}$.

The hydrothermal multi-cycle stability is another key issue, as several thousand adsorption-desorption cycles will be performed during the lifetime of an AHP or a TDC.

Most porous materials were originally developed for different applications and thus they feature adsorption characteristics not matching the demands of heat transformation processes. However, within the last decade several exciting improvements with the development of new porous materials like aluminophosphates

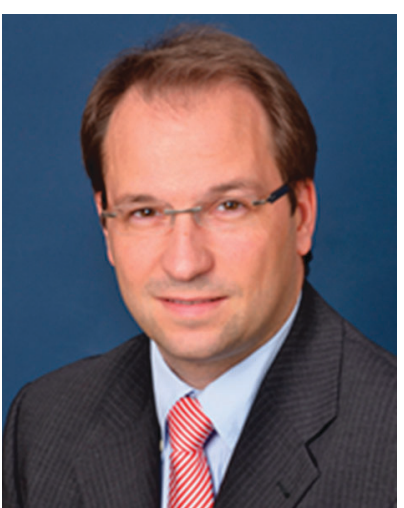

Stefan K. Henninger
Stefan Henninger studied physics and did his PhD at the Freiburg Material Research Center, using $G C$ Monte Carlo simulations to identify adsorbents for heat transformation applications. He is currently leading the group sorption materials characterisation and development at the Fraunhofer Institute for Solar Energy Systems. 
(AlPOs), silica-aluminophosphates (SAPOs) and metal-organic frameworks (MOFs) have appeared. ${ }^{6,7}$

\section{Silica gel and zeolites}

The present generation of adsorption chillers mostly uses silica gels as adsorbents, and finding improved silica gels for heat pumping and cooling applications has been a research priority for many years. ${ }^{8}$

The key problem of silica gels, synthesized either by polymerization of silicic acid, $\mathrm{Si}\left(\mathrm{OH}_{4}\right)$, or aggregation of colloidal silica particles, is that most of the water adsorption occurs at too high relative pressures. Thus, the working fluid exchange over the cycle is only a small part of the total working capacity. Various modifications were investigated to overcome this issue, such as increasing the amount of silanol groups on the surface or reducing the pore sizes. The silica gels showing the strongest water adsorption at low pressures were found to be those that have very small pores (microporous silica) and contain trace impurities like aluminium or other metals. ${ }^{9}$

Among the various zeolitic adsorbents, only zeolites with large pore volumes need to be considered for adsorptive cooling cycles. These are primarily the commercially available zeolites of types $\mathrm{A}, \mathrm{X}$, and $\mathrm{Y}$. Zeolites $\mathrm{X}$ and $\mathrm{Y}$ both belong to the faujasite (FAU) crystal structure type, are the most commonly available synthetic zeolites and have been considered for adsorptive heat pumping and cooling cycles since the 1980's. ${ }^{10}$

Zeolites feature a comparatively high maximum water adsorption capacity, but the strong hydrophilicity significantly reduces the fluid exchange within the cycle for desorption temperatures below $140{ }^{\circ} \mathrm{C} .{ }^{11}$ Several modifications, either by ion exchange or de-alumination, were investigated to reduce the required desorption temperatures. In addition, the fabrication of materials without the use of any adhesive was investigated to reduce the inactive parts of, e.g., shaped materials. ${ }^{12}$

\section{AlPO and SAPO}

Zeolite-like crystalline aluminophosphates (AlPO) and silicaaluminophosphates (SAPO) are considered for heat transformation within the last decade, with the potential to overcome the aforementioned problems of the classical adsorbents. ${ }^{13}$

AlPO-5, AlPO-17, AlPO-18 and APO-TRIC were identified as the most promising members of this family. ${ }^{14}$ Their adsorption behaviour changes from hydrophobic to hydrophilic at a characteristic $p / p_{0}$, which leads to the desired s-shape adsorption isotherms..$^{15}$ In addition, they can provide a higher maximum water uptake capacity than zeolites.

Modification of the structure and the sorption properties can be realized by isomorphous substitution of metal atoms in the framework. This leads to a negatively charged framework, so a charge-balancing extra-framework cation is introduced, increasing the polarity and, hence, the hydrophilicity of the framework. Consequently, silica-aluminophosphates, SAPOs, are typically more hydrophilic than AlPOs. In fact, SAPO-34, which is among the best-known compounds, still shows an $\mathrm{s}$-shaped isotherm, with the steep increase of the isotherm shifted towards lower $p / p_{0}$.
These characteristics show the excellent suitability of AlPOs and SAPOs for heat transformation applications. Due to the templated syntheses, these materials are unfortunately very expensive, and their adsorption capacity remains so far limited.

\section{MOFs}

Crystalline, three-dimensional and porous metal-ligand coordination networks with metal nodes and bridging organic ligands (Fig. 2) are called metal-organic frameworks (MOFs). Typically, they feature a uniform pore structure throughout the crystalline framework. ${ }^{16}$ The pore size, shape and chemical nature of the inner pore surface can be tuned by variation of the organic ligands. This new class of porous materials is being investigated for numerous potential applications ${ }^{17-19}$ such as for gas storage $e^{20}$ and separation processes, drug delivery, heterogeneous catalysis, and, recently, water sorption for heat transformation ${ }^{3,21-26}$ which was first suggested by Aristov. ${ }^{25}$ MOFs initially contain solvent molecules or linker residues inside the pores. After synthesis of the material, the pores have to be emptied through washing and evacuation procedures (activated) to give accessible micropore volumes with BET surface areas ranging typically between 1000 and $4000 \mathrm{~m}^{2} \mathrm{~g}^{-1}$. Pore apertures or channel diameters of MOFs range from 0.3 to $3.4 \mathrm{~nm}$ with pore volumes of up to 1.5 or $2 \mathrm{~cm}^{3} \mathrm{~g}^{-1}$. Water stability is, however, a problem for MOFs. Many are not stable at all or appear water stable only because of their hydrophobicity. ${ }^{27}$<smiles>CC(=O)c1cc(C(=O)O)cc(C(=O)O)c1</smiles>

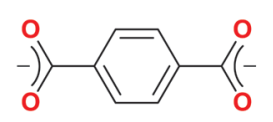

benzene-1,3,5-dicarboxylate, trimesate, BTC $+$ $\mathrm{Cu}^{2+}$
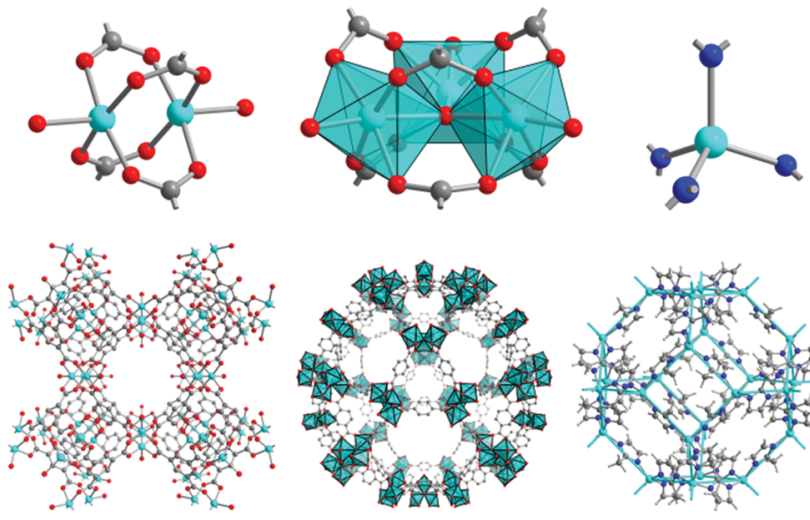

HKUST-1, CU-BTC

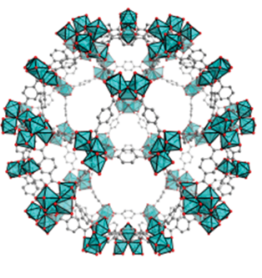

MIL-101Cr

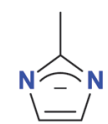

2-methylimidazolate $7 n^{2}+$
Fig. 2 Prototypical linkers with selected metal nodes and secondary building units in corresponding MOFs (with acronyms). For ZIF- 8 the sodalite cage is highlighted. 


\section{Adsorption characteristics of MOFs}

\section{MOFs with water as a working fluid}

One of the first MOFs tested for reversible water sorption in the realm of heat transfer was the mixed-ligand MOF ISE- $1\left(\left[\mathrm{Ni}_{3}\left(\mu_{3}-\right.\right.\right.$ $\left.\mathrm{BTC})_{2}\left(\mu_{4}-\mathrm{BTRE}\right)_{2}\left(\mu-\mathrm{H}_{2} \mathrm{O}\right)_{2}\right]$, BTRE $=$ bis(triazolyl)ethane $)$ with a crystal water content of about $30 \mathrm{wt} \%$ which can be reversibly removed over at least 10 cycles. $^{28}$

The group of Férey introduced a series of porous materials, known as MILs (for Material Institute Lavoisier), comprised of three- and four-valent metal ions $\left(\mathrm{Ti}^{4+}, \mathrm{Cr}^{3+}, \mathrm{Fe}^{3+}, \mathrm{Al}^{3+}\right)$, and aromatic di- and tri-carboxylate linkers. ${ }^{19,29}$ MIL materials form under quite harsh synthesis conditions in water $(\mathrm{pH}<1, T>$ $150{ }^{\circ} \mathrm{C}$ ) so good hydrothermal stability can be anticipated. MILS can accept water in the range of $1.0-1.5 \mathrm{~g} \mathrm{~g}^{-1}$ for MIL-101Cr (Fig. 3), 0.6-0.7 $\mathrm{g} \mathrm{g}^{-1}$ for MIL-100Cr, 0.65-0.75 $\mathrm{g} \mathrm{g}^{-1}$ for MIL$100 \mathrm{Fe}$ and $0.5 \mathrm{~g} \mathrm{~g}^{-1}$ für MIL-100Al. ${ }^{3,26,30}$ In contrast to zeolites, MOFs typically exhibit s-shaped water adsorption isotherms. The water uptake capacity of MOFs is not only determined by the available porosity, but also by the hydrophobicity/hydrophilicity of the ligand, the hydrogen-bonding capabilities of functional groups and a possible structural transition of the adsorbent material. ${ }^{31}$ In order to tune the water uptake to lower $p / p_{0}$ values, the organic linker can be modified with hydrophilic amino- or hydroxo-groups ( $c f$. Fig. 3). A nice example was illustrated with the replacement of hydrophobic 2-methylimidazolate in MAF-4 (ZIF-8) by hydrophilic 3-methyl-1,2,4-triazolate in MAF-7 (Fig. S3 in ESI $\dagger)^{24}$

\section{MOFs with methanol as a working fluid}

A large share of potentially interesting MOFs exhibit desirable properties like a high initial working fluid uptake, but cannot be used in water-based heat pump processes due to their inherent lack of multicycle hydrothermal stability. ${ }^{23}$ Thus, the working fluid methanol may be a good prospect for hydrothermally unstable materials.

Chromium terephthalate MIL-53Cr was one of the first MOFs investigated with methanol as an adsorptive and exhibited a

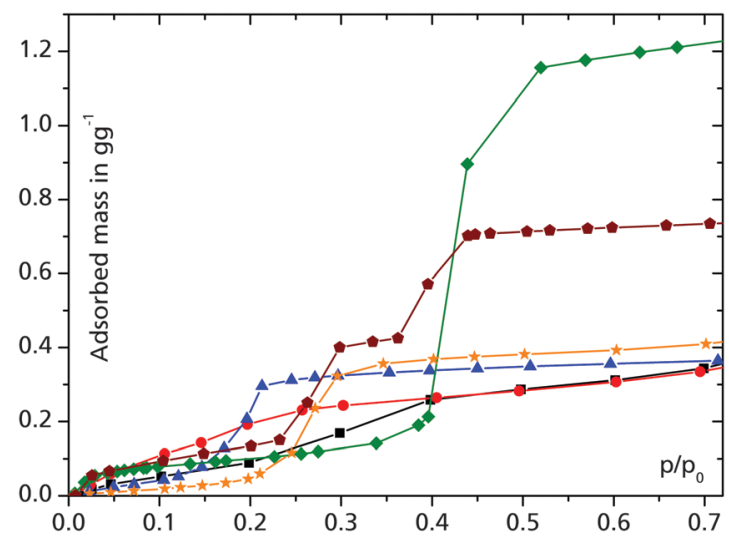

Fig. 3 Water adsorption isotherms for selected MOFs at $25^{\circ} \mathrm{C}$ : UiO- $66^{21}$

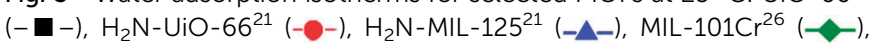
Al-fumarate ${ }^{32}$ (- - ) and MIL-100 Fe ${ }^{3}$ (- - - ).

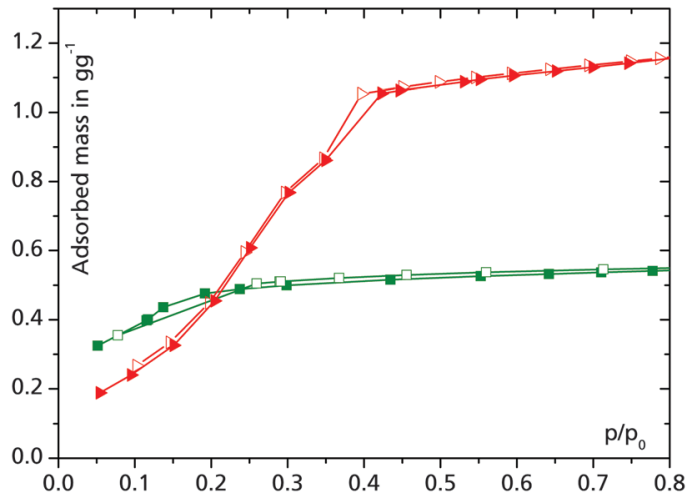

Fig. 4 Methanol adsorption isotherms acquired at $25{ }^{\circ} \mathrm{C}$ for selected MOFs: HKUST-1 (- $)$ and MIL-101Cr (-). Adsorption is depicted with full symbols, desorption with empty symbols.

loading lift of $0.53 \mathrm{~g} \mathrm{~g}^{-1}$, with the main uptake occurring at relative pressures as low as $p / p_{0}<0.20 .^{33}$

MIL-101Cr is among the most interesting MOFs when it comes to heat transformation, mainly because of its stability and high porosity $\left(S_{\mathrm{BET}}>3000 \mathrm{~m}^{2} \mathrm{~g}^{-1}\right){ }^{26,34}$ While water uptake is negligible at relative pressures lower than $p / p_{0}=0.4$ (cf. Fig. 3), it turned out that $1.0 \mathrm{~g} \mathrm{~g}^{-1}$ of $\mathrm{MeOH}$ are already adsorbed at this pressure (Fig. 4). ${ }^{35}$

Well-examined copper trimesate HKUST-1 features a type-I adsorption isotherm for $\mathrm{MeOH}$ and exhibits a loading lift of approx. $0.5 \mathrm{~g} \mathrm{~g}^{-1}$ (Fig. 4). As the substance is commercially available and turned out to retain its crystallinity even after several thousands of adsorption-desorption cycles (see the Stability characteristics of MOFs section below), it is among the most promising candidates for $\mathrm{MeOH}$ based appliances.

\section{Stability characteristics of MOFs}

One of the key challenges for the applicability of any adsorbent in a heat transformation process is to achieve its permanent stability towards cyclic adsorption of the working fluid. The search for hydrothermally stable MOFs, however, is of general interest for a lot of different industrial applications, where at least traces of water are usually present. ${ }^{27}$

The hydrothermal stability of a given MOF depends on the inertness of the coordinative metal-linker bond against hydrolysis and on the hydrophobicity of the framework. Hence, binding energies, coordination geometries, d-configurations and steric effects play important roles. The first estimation of hydrothermal stability can be based on coordination chemistry principles for the metal-linker combination. As a result, the stability increases from $\mathrm{Zn}$ (II) carboxylate MOFs over $\mathrm{Cu}(\mathrm{II})$ to Cr(III) carboxylate MOFs.

Hydrothermal stability can also be improved by shielding the metal-linker bond from water vapor using sterically demanding and hydrophobic linkers. However, as in many cases, an aqua ligand or a free coordination site on the metal atom serves as an anchor for water cluster formation, hydrophilicity is usually strongly reduced in such cases, and the MOF 


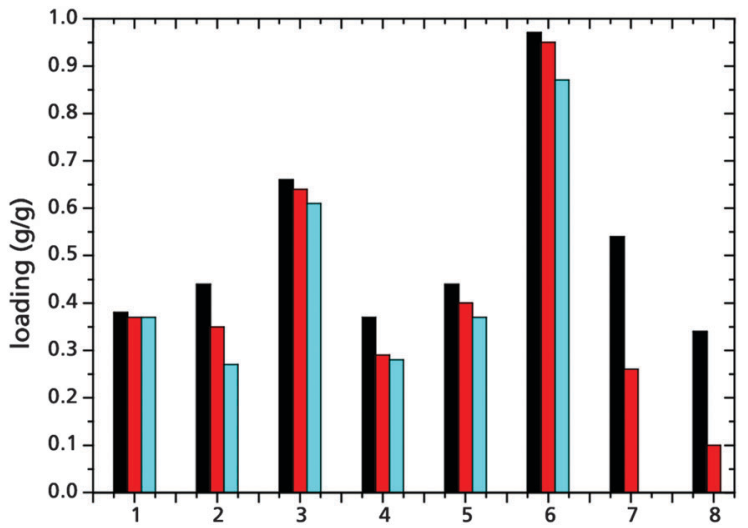

Fig. 5 Water loading spread measured on aluminium fumarate (1), ${ }^{32} \mathrm{UiO}$ 66 (2), ${ }^{21} \mathrm{MIL}-100 \mathrm{Fe}(3)^{3}$ and $\mathrm{Al}(4),{ }^{3} \mathrm{H}_{2} \mathrm{~N}-\mathrm{MIL}-125$ (5), ${ }^{21} \mathrm{MIL}-101 \mathrm{Cr}(6),{ }^{26}$ HKUST-1 $(7)^{23}$ and Basolite ${ }^{\circledR}$ F3OO $(8)^{23}$ after activation (ם), after 20 adsorption-desorption cycles with water vapor ( $\square$ ), and after 40 adsorption-desorption cycles ( $\square$ ).

may not adsorb any water at all. ${ }^{36}$ For example, zinc imidazolate ZIF-8 is hydrothermally stable because no water is adsorbed. ${ }^{24} \mathrm{~A}$ zinc trimesate (and other MOFs) showed increased hydrothermal stability when water adsorption is prevented due to interpenetration or pore blocking. ${ }^{37}$

For use in adsorption heat pumps/chillers, hydrothermal stability cannot be deduced merely by retrieving the MOF from an aqueous suspension without structural damage but needs to be verified through a larger number of water vapor adsorptiondesorption cycles (Fig. 5). The difference in cyclic hydrothermal stability may be explained by the phase change enthalpy released at the adsorption site, i.e., at the framework itself. Corresponding values have been calculated to lie in the range of ligand displacement energies. Furthermore, water molecules are actively being conveyed towards and away from the porous material during cyclic adsorption-desorption processes. Thus, the probability of $\mathrm{M}-\mathrm{L}$ bond hydrolysis increases and pores are stressed by the alternating forces created through cavitation and capillary forces. MIL-101Cr, MIL-100Al, Fe, aluminium fumarate and some 4th group MOFs are among the most stable compounds examined so far (Fig. 5).

\section{Shaping for optimized heat and mass transport}

Clearly, the maximum power of an adsorption heat pump or chiller depends proportionally on how much working fluid can be adsorbed and desorbed at a given time. Sorption kinetics is governed by two main aspects, ${ }^{38}$ the first being mass transport towards and away from the adsorption site by inter- and intracrystalline transport phenomena, which are subject to the laws of molecular, Knudsen or surface diffusion. Possibilities for improvement include, among others, decreasing the diffusion path lengths, for example by the employment of nanocrystals and by optimization of the outer surface of the adsorber. ${ }^{39}$ The second, even more important aspect is conveyance of heat of adsorption, i.e., the thermal coupling between the adsorption site and the heat exchanger. Current AHPs/TDCs feature either packed-bed or coated heat exchanger concepts. In principle, packed-bed adsorbers prepared from MOFs can also be made, as pellets are available. Upon the transition from silica gel to zeolites with their working fluid uptake in the range of 0.2 to $0.4 \mathrm{~g} \mathrm{~g}^{-1}$, coated heat exchangers prepared via direct crystallization have proven superior to packed beds already. ${ }^{7,18,40}$ However, since heat conductivities of packed-bed adsorbers are usually inferior ${ }^{41}$ due to point-like thermal contacts, MOF packed beds are being examined mainly for applications where heat transfer comes second to capacity, e.g., storage and separation of non-polar adsorptives like $\mathrm{CH}_{4}, \mathrm{~N}_{2}, \mathrm{H}_{2}$ or $\mathrm{CO}_{2}{ }^{42}$ In the case of heat pumps/chillers, a much higher heat flow must be ensured. ${ }^{43}$

With their higher capacities, MOF-based adsorbents require to be shaped even more into 100-200 $\mu \mathrm{m}$ thick, sturdy, thermally well coupled and fully accessible coatings. Procedures for the preparation of such layers are scarce, as research on MOF coatings is mainly focused on delicate applications like sensing, luminescence, gas separation, etc., which require thin $(<1 \mu \mathrm{m})$, oriented, even monocrystalline films grown on functionalized substrates. ${ }^{44}$ One recent approach is the thermal gradient method, based on the significant temperature dependence of crystal growth, thus allowing for direct crystallisation just on the surface. The method is beneficial for the preparation of coated heat exchangers, as these are made for the purpose of internal heating. Indeed, coatings of representative MOFs like HKUST-1 and aluminium fumarate can be synthesized on different metallic substrates, with rates of approximately $50 \mu \mathrm{m} \mathrm{h}^{-1}$ (see Fig. S4 in ESI $\dagger$ ). ${ }^{32,45}$ In the future, binder-based MOF coatings may also prove valuable.

\section{Conclusions}

Because of their unprecedented high porosities and narrow pore size distributions, MOFs can pave the way towards highly efficient thermally driven heat pumps. High uptake at medium vapor pressures renders them suitable especially for chilling applications, but the inherent chemical variability opens the way towards neatly tuned adsorbents for the application over a large range of different boundary conditions. Still, their hydrothermal stability remains a key issue for a broad range of applications. Out of the large number of possible structures, several compounds have been identified showing very promising initial water vapor stability. The use of alcohols as working fluids may be a good prospect for the application of otherwise promising, but hydrothermally unstable or not sufficiently hydrophilic materials like HKUST-1 or MIL-101Cr, respectively, or for low temperature applications, where the vapor pressure of $\mathrm{H}_{2} \mathrm{O}$ is not sufficient for acceptable kinetics. Finally, heat and mass transfer can be optimized by various shaping procedures, which render MOFs very exciting for use in future heat transformation.

\section{Acknowledgements}

This work was supported by the Fraunhofer Internal Programs under Grant-\# MAVO 824704, and by the German Federal Ministry of Economics under Grant-\# 0327851A/B. 


\section{Notes and references}

1 I. E. Agency, Key World Energy Statistics, OECD/IEA, 2013.

2 L. Perez-Lombard, J. Ortiz and C. Pout, Energy Build., 2008, 40, 394-398; C. A. Balaras, G. Grossman, H.-M. Henning, C. A. Infante Ferreira, E. Podesser, L. Wang and E. Wiemken, Renewable Sustainable Energy Rev., 2007, 11, 299-314.

3 F. Jeremias, A. Khutia, S. K. Henninger and C. Janiak, J. Mater. Chem., 2012, 22, 10148.

4 L. W. Wang, J. Y. Wu, R. Z. Wang, Y. X. Xu, S. G. Wang and X. R. Li, Appl. Therm. Eng., 2003, 23, 1605-1617; R. E. Critoph and Y. Zhong, Proc. Inst. Mech. Eng., Part E, 2005, 219, 285-300; S. K. Henninger, M. Schicktanz, P. P. C. Hugenell, H. Sievers and H. M. Henning, Int. J. Refrig., 2012, 35, 543-553; Z. Tamainot-Telto, S. J. Metcalf, R. E. Critoph, Y. Zhong and R. Thorpe, Int. J. Refrig., 2009, 32, 1212-1229.

5 E. J. Hu, Sol. Energy, 1998, 62, 325-329.

6 E.-P. Ng and S. Mintova, Microporous Mesoporous Mater., 2008, 114, 1-26; J. Janchen, D. Ackermann, H. Stach and W. Brosicke, Sol. Energy, 2004, 76, 339-344; Y. I. Aristov, G. Restuccia, G. Cacciola and V. N. Parmon, Appl. Therm. Eng., 2002, 22, 191-204; B. B. Saha, S. Koyama, J. B. Lee, K. Kuwahara, K. C. A. Alam, Y. Hamamoto, A. Akisawa and T. Kashiwagi, Int. J. Multiphase Flow, 2003, 29, 1249-1263; Y. I. Aristov, Appl. Therm. Eng., 2013, 50, 1610-1618.

7 S. K. Henninger, F. P. Schmidt and H. M. Henning, Appl. Therm. Eng., 2010, 30, 1692-1702.

8 K. C. Ng, H. T. Chua, C. Y. Chung, C. H. Loke, T. Kashiwagi, A. Akisawa and B. B. Saha, Appl. Therm. Eng., 2001, 21, 1631-1642; Y. I. Aristov, M. M. Tokarev, A. Freni, I. S. Glaznev and G. Restuccia, Microporous Mesoporous Mater., 2006, 96, 65-71; L. G. Gordeeva, A. Freni, Y. I. Aristov and G. Restuccia, Ind. Eng. Chem. Res., 2009, 48, 6197-6202.

9 B. Dawoud and Y. Aristov, Int. J. Heat Mass Transfer, 2003, 46, 273-281.

10 G. Restuccia and R. Quagliata, Int. J. Energy Res., 1988, 12, 101-111; R. E. Critoph and R. Vogel, Int. J. Ambient Energy, 1986, 7, 183-190; F. Meunier, J. Sol. Energy Res., 1983, 1, 23-25; E. Dahome and F. Meunier, Rev. Gen. Therm., 1982, 21, 485-500; J. J. Guilleminot and F. Meunier, Rev. Gen. Therm., 1981, 20, 825-834.

11 S. K. Henninger, F. Jeremias, H. Kummer, P. Schossig and H.-M. Henning, Energy Procedia, 2012, 30, 279-288.

12 J. Jänchen, K. Schumann, E. Thrun, A. Brandt, B. Unger and U. Hellwig, Int. J. Low-Carbon Technol., 2012, 275-279; J. Janchen, H. Stach and U. Hellwig, Stud. Surf. Sci. Catal., 2008, 174, 599-602; S. K. Henninger, F. P. Schmidt and H. M. Henning, Adsorption, 2011, 17, 833-843; K. Schumann, B. Unger, A. Brandt and F. Scheffler, Microporous Mesoporous Mater., 2012, 154, 119-123; K. Schumann, A. Brandt, B. Unger and F. Scheffler, Chem. Ing. Tech., 2011, 83, 2237-2243.

13 S. T. Wilson, B. M. Lok, C. A. Messina, T. R. Cannan and E. M. Flanigen, J. Am. Chem. Soc., 1982, 104, 1146-1147.

14 S. Shimooka, K. Oshima, H. Hidaka, T. Takewaki, H. Kakiuchi, A. Kodama, M. Kubota and H. Matsuda, J. Chem. Eng. Jpn., 2007, 40, 1330-1334; H. Kakiuchi,
S. Shimooka, M. Iwade, K. Oshima, M. Yamazaki, S. Terada, H. Watanabe and T. Takewaki, Kagaku Kogaku Ronbunshu, 2005, 31, 361-364; H. van Heyden, S. Mintova and T. Bein, J. Mater. Chem., 2006, 16, 514-518; A. Ristic, N. Z. Logar, S. K. Henninger and V. Kaucic, Adv. Funct. Mater., 2012, 22, 1952-1957.

15 S. G. Izmailova, E. A. Vasiljeva, I. V. Karetina, N. N. Feoktistova and S. S. Khvoshchev, J. Colloid Interface Sci., 1996, 179, 374-379.

16 J. R. Long and O. M. Yaghi, Chem. Soc. Rev., 2009, 38, 1213-1214; K. Biradha, New J. Chem., 2010, 34, 2353-2354; H. C. Zhou, J. R. Long and O. M. Yaghi, Chem. Rev., 2012, 112, 673-674; S. Kitagawa and S. Natarajan, Eur. J. Inorg. Chem., 2010, 3685.

17 C. Janiak, Dalton Trans., 2003, 2781-2804; C. Janiak and J. K. Vieth, New J. Chem., 2010, 34, 2366-2388; M. J. Prakash and M. S. Lah, Chem. Commun., 2009, 3326-3341.

18 A. U. Czaja, N. Trukhan and U. Muller, Chem. Soc. Rev., 2009, 38, 1284-1293.

19 G. Férey, Dalton Trans., 2009, 4400-4415.

20 J. R. Li, R. J. Kuppler and H. C. Zhou, Chem. Soc. Rev., 2009, 38, 1477-1504; M. P. Suh, H. J. Park, T. K. Prasad and D. W. Lim, Chem. Rev., 2012, 112, 782-835; H. Wu, Q. Gong, D. H. Olson and J. Li, Chem. Rev., 2012, 112, 836-868; L. J. Murray, M. Dinca and J. R. Long, Chem. Soc. Rev., 2009, 38, 1294-1314.

21 F. Jeremias, V. Lozan, S. Henninger and C. Janiak, Dalton Trans., 2013, 42, 15967-15973.

22 C. Janiak and S. K. Henninger, Chimia, 2013, 67, 419-424; G. Akiyama, R. Matsuda, H. Sato, A. Hori, M. Takata and S. Kitagawa, Microporous Mesoporous Mater., 2012, 157, 89-93; E. Biemmi, A. Darga, N. Stock and T. Bein, Microporous Mesoporous Mater., 2008, 114, 380-386.

23 S. K. Henninger, F. Jeremias, H. Kummer and C. Janiak, Eur. J. Inorg. Chem., 2012, 2625-2634.

24 J.-P. Zhang, A.-X. Zhu, R.-B. Lin, X.-L. Qi and X.-M. Chen, Adv. Mater., 2011, 23, 1268-1271.

25 Y. I. Aristov, J. Chem. Eng. Jpn., 2007, 40, 1242-1251.

26 J. Ehrenmann, S. K. Henninger and C. Janiak, Eur. J. Inorg. Chem., 2011, 471-474.

27 J. J. Low, A. I. Benin, P. Jakubczak, J. F. Abrahamian, S. A. Faheem and R. R. Willis, J. Am. Chem. Soc., 2009, 131, 15834-15842.

28 S. K. Henninger, H. A. Habib and C. Janiak, J. Am. Chem. Soc., 2009, 131, 2776-2777.

29 G. Férey and C. Serre, Chem. Soc. Rev., 2009, 38, 1380-1399. 30 G. Akiyama, R. Matsuda and S. Kitagawa, Chem. Lett., 2010, 360-361.

31 P. M. Schoenecker, C. G. Carson, H. Jasuja, C. J. J. Flemming and K. S. Walton, Ind. Eng. Chem. Res., 2012, 51, 6513-6519; G. E. Cmarik, M. Kim, S. M. Cohen and K. S. Walton, Langmuir, 2012, 28, 15606-15613; H. Jasuja, J. Zang, D. S. Sholl and K. S. Walton, J. Phys. Chem. C, 2012, 116, 23526-23532.

32 F. Jeremias, D. Fröhlich, S. K. Henninger, C. Janiak, 2014, unpublished work. 
33 S. Bourrelly, B. Moulin, A. Rivera, G. Maurin, S. DevautourVinot, C. Serre, T. Devic, P. Horcajada, A. Vimont, G. Clet, M. Daturi, J. C. Lavalley, S. Loera-Serna, R. Denoyel, P. L. Llewellyn and G. Férey, J. Am. Chem. Soc., 2010, 132, 9488-9498.

34 G. Férey, C. Mellot-Draznieks, C. Serre, F. Millange, J. Dutour, S. Surble and I. Margiolaki, Science, 2005, 309, 2040-2042.

35 S. K. Henninger, 2014, unpublished work.

36 P. Küsgens, M. Rose, I. Senkovska, H. Fröde, A. Henschel, S. Siegle and S. Kaskel, Microporous Mesoporous Mater., 2009, 120, 325-330.

37 H. Jasuja and K. S. Walton, Dalton Trans., 2013, 42, 15421-15426; T. Birsa Čelič, M. Mazaj, N. Guillou, E. Elkaïm, M. El Roz, F. Thibault-Starzyk, G. Mali, M. Rangus, T. Čendak, V. Kaučič and N. Zabukovec Logar, J. Phys. Chem. C, 2013, 117, 14608-14617.

38 M. H. Chahbani, J. Labidi and J. Paris, Appl. Therm. Eng., 2002, 22, 23-40.

39 Y. I. Aristov, Int. J. Refrig., 2009, 32, 675-686.

40 B. Dawoud, Appl. Therm. Eng., 2013, 50, 1645-1651; L. Bonaccorsi, L. Calabrese, A. Freni, E. Proverbio and G. Restuccia, Appl. Therm. Eng., 2013, 50, 1590-1595;
B. Yilmaz, N. Trukhan and U. Müller, Chin. J. Catal., 2012, 33, 3-10; G. W. Peterson, J. B. DeCoste, T. G. Glover, Y. G. Huang, H. Jasuja and K. S. Walton, Microporous Mesoporous Mater., 2013, 179, 48-53.

41 S. Kaskel, Chem. Ing. Tech., 2010, 82, 1019-1023; L. Pino, Y. Aristov, G. Cacciola and G. Restuccia, Adsorption, 1997, 3, 33-40.

42 L. Bastin, P. S. Barcia, E. J. Hurtado, J. A. C. Silva, A. E. Rodrigues and B. Chen, J. Phys. Chem. C, 2008, 112, 1575-1581.

43 A. Atakan, G. Fueldner, G. Munz, S. Henninger and M. Tatlier, Appl. Therm. Eng., 2013, 58, 273-280; A. ErdemSenatalar, M. Tatlier and M. Ürgen, Microporous Mesoporous Mater., 1999, 32, 331-343.

44 D. Bradshaw, A. Garai and J. Huo, Chem. Soc. Rev., 2012, 41, 2344-2381; A. Bétard and R. A. Fischer, Chem. Rev., 2012, 112, 1055-1083; D. Zacher, R. Schmid, C. Wöll and R. A. Fischer, Angew. Chem., Int. Ed., 2011, 50, 176-199; O. Shekhah, J. Liu, R. A. Fischer and C. Wöll, Chem. Soc. Rev., 2011, 40, 1081-1106; D. Zacher, O. Shekhah, C. Wöll and R. A. Fischer, Chem. Soc. Rev., 2009, 38, 1418-1429.

45 F. Jeremias, S. K. Henninger and C. Janiak, Chem. Commun., 2012, 48, 9708-9710. 